\title{
Exégesis histórica en el Código Orgánico General de Procesos: naturaleza jurídica y estructura del proceso monitorio
}

Historical Exegesis in the Organic Code of General Processes: Legal nature and structure of the order for payment procedure

\author{
Gabriel Andrés Reina Vanegas \\ Ortega Abogados \& Asociados
}

\section{Resumen}

El presente artículo trata de dar luces sobre la naturaleza jurídica y la estructura del proceso monitorio en el nuevo Código Orgánico General de Procesos (COGEP). Este análisis es realizado a través de un método tradicional de interpretación legal hallado en el Código Civil del Ecuador: el método histórico-exegético. Se analiza la evolución del procedimiento monitorio con el uso de los trabajos preparatorios o materiales legislativos del COGEP. Este estudio abarca su génesis en los primeros proyectos de ley hasta su publicación en el Registro Oficial.

\section{Palabras clave}

Procedimiento monitorio / Interpretación legal / Trabajos preparatorios.

\section{Summary}

The following article tries to shed light on the legal nature and structure of the order for payment process found in the new Organic Code of General Processes (COGEP) called proceso monitorio. This analysis is done through a traditional method of legal interpretation found in the Civil Code of Ecuador: historical interpretation. The evolution of the order for payment procedure is analyzed through the use of travaux préparatories or legislative materials of the COGEP. This study covers its origins which are found in the first draft bills up to its publication in the Official Gazette.

\section{Keywords}

Order for payment procedure / Legal interpretation / Travaux préparatories.

\section{Introducción}

El Código Orgánico General de Procesos (oficialmente abreviado: COGEP) entró en vigencia el 22 de mayo de 2016, un año exacto después de haber sido publicado en el Suplemento del Registro Oficial No. 506 del 22 de mayo de 2015. Una de las características más dominantes de esta ley adjetiva fue la inclusión de un nuevo tipo de procedimiento al derecho positivo ecuatoriano: el procedimiento monitorio.

Dentro de la geografía del código, el procedimiento monitorio se encuentra regulado en el Capítulo II ("Procedimiento monitorio") del Título II ("Procedimientos ejecutivos") de su Libro IV ("Procesos"); su capítulo encierra a los artículos del 356 al 361. Dicho procedimiento, como ya fue mencionado, es nuevo, no corresponde a ninguno de los que hayan sido usados antes en el territorio nacional; carece totalmente de análogos en la legislación histórica ecuatoriana.

Siendo este el estado de las cosas y habiendo trascurrido relativamente poco tiempo desde la publicación del COGEP, en la actualidad, el procedimiento monitorio nacional sufre 
de una notoria oscuridad académica y jurisprudencial: existe un exiguo aporte de fuentes netamente ecuatorianas al entendimiento y desarrollo de esta nueva institución procesal ${ }^{1}$.

\section{La ley oscura}

Hablar de oscuridad en la ley obliga a referirnos a los principios de interpretación legal establecidos en el Art. 18, no 1, del Código Civil del Ecuador. El texto de la referida norma, tal como se encuentra publicado en el Suplemento del Registro Oficial No. 46 del 24 de junio de 2005, reza que es permitido lo siguiente: "[...] para interpretar una expresión oscura de la ley, recurrir a su intención o espíritu claramente manifestados en ella misma, o en la historia fidedigna de su establecimiento".

Don Luis Felipe Borja, tratadista ecuatoriano, en sus comentarios a este artículo, señaló las virtudes del mencionado método de interpretación legal declarando lo siguiente: “[...] el elemento histórico es uno de los medios más poderosos para interpretar la ley, reconstruyendo el pensamiento del legislador". A continuación, indica que: "La historia fidedigna del Código chileno se halla en el proyecto de D. Andrés Bello" (1901, p. 365). Por lo tanto, este autor cita como fundamento de su comentario al mismo Proyecto de Código Civil (1853) de Don Andrés Bello, quien fue el legislador material del Código Civil de Chile, y por extensión, del nuestro. En su proyecto, Bello explica que "La historia fidedigna del establecimiento de una lei [sic] sería, por ejemplo, la relación de los debates ocurridos en el Cuerpo Lejislativo [sic] al tiempo de discutirse el Proyecto" (1888, p. 8).

\section{La importancia de la interpretación histórico-exegética}

Dicho método de interpretación no es exclusivo de la legislación derivada del Código Civil de Chile, ni de la legislación hispanoamericana; este se encuentra avalado por los más insignes doctrinarios de Europa. En Alemania, Ludwig Enneccerus, Theodor Kipp, y Martin Wolff, al tratar sobre la interpretación de la ley, recalcan la importancia de los materiales legislativos:

De la expuesta misión de la interpretación resulta una estimación moderada, que ni exagera, ni rechaza el valor de los llamados materiales legislativos, o sea los trabajos previos, los proyectos, los motivos, las memorias y las deliberaciones en las comisiones legislativas o parlamentarias, que precedieron al acto legislativo ejerciendo influencia sobre el mismo (1953, p. 201).

De la misma forma, en Francia, Marcel Planiol y Georges Ripert establecen que, en casos de duda u oscuridad legislativa, es procedente emplear los trabajos preparativos de la ley:

Lo primero que debe hacerse para suprimir la duda, es consultar los trabajos preparatorios de la ley (discusiones de las cámaras, informes, exposición de motivos). Con frecuencia en estos documentos se encuentra explicado el pensamiento en que se basa el legislador (1999, p. 26).

\footnotetext{
1 Actualmente existen pocas publicaciones académicas sobre el procedimiento monitorio. De entre estas pocas, sobresalen las siguientes: Brigante Guerra, R. (2015). Sinopsis de la naturaleza y trámite del procedimiento monitorio en el nuevo Código Orgánico General de Procesos del Ecuador. En T. Quintero Jaramillo (Ed.), Memorias del Congreso Internacional de Derecho Procesal COGEP: Sistema de Audiencias en el Derecho Procesal Ecuatoriano. Legislación 2015 (pp. 7-19). Samborondón: Universidad de Especialidades Espíritu Santo; Aguirre Guzmán, V. (2016). El procedimiento monitorio en el Código Orgánico General de Procesos: ¿Una vía idónea para el cobro eficaz de las deudas de pequeña cuantía?. Boletín Informativo de la Asociación de Bancos Privados del Ecuador 63 (Mayo 2016), pp. 5-7; Suárez Armijos, R. B. (2017). El proceso monitorio en el Ecuador. Corte Nacional de Justicia: Boletin Institucional 29 (Mayo-junio 2017), pp. 6-7.
} 
En Italia, la autorizada opinión de Francesco Messineo también concede que las normas puedan ser explicadas por la influencia del elemento histórico, en particular a través de "[...] los llamados trabajos preparatorios, o sea el conjunto de los testimonios dejados de la elaboración de las normas por parte de los redactores de ellas [...]" (1979, p. 104). No obstante, continua que la fuerza interpretativa de estos documentos es relativa al texto de la misma ley:

[...] sobre los trabajos preparatorios, predomina la voluntad objetiva de la ley. Así, en el contraste entre formulación de la norma y propósito manifestado por el legislador en los trabajos preparatorios, prevalece la formulación. Pero el propósito, cuando es concorde con el texto (formulación) de la norma, tiene un notable valor explicativo y ofrece un fundamento muy sólido a la interpretación (1979, p. 104).

Así como este método no está limitado por las fronteras de las naciones ${ }^{2}$, tampoco está limitado por la materia: este método no es exclusivo del derecho civil-sustantivo. Así lo confirma el argentino Hugo Alsina, al incluirlo dentro de los métodos para interpretar las leyes procesales:

Grande fue también el prestigio del método llamado exegético que investiga el sentido de la ley examinando su génesis. Se explica, así, el valor que se atribuye a los trabajos preparatorios, a las discusiones parlamentarias y especialmente al informe de la comisión encargada de su estudio en el Parlamento. Nuestros jueces recurren a este procedimiento con bastante frecuencia a causa de que uno de los principales defectos de nuestras leyes es la falta de técnica jurídica, y el examen de los antecedentes parlamentarios permite establecer en esos casos cuál ha sido el propósito del legislador; pero vamos a ver también que este método, si bien permite establecer cuál ha sido ese propósito en el momento de la sanción de la ley, puede resultar ineficaz cuando las condiciones han variado (1956-1965, vol. I, pp. 86-87).

Los documentos legislativos, por ende, sirven para interpretar la norma a través de la aparente voluntad o propósito del legislador, sea este el legislador material (i.e. el redactor o ideario original de la ley) o el formal (i.e. los diputados o senadores reunidos en congreso o asamblea); dos siendo sus limitantes: el texto legal publicado y los hechos futuros no previstos por el legislador.

\section{La evolución normativa del procedimiento monitorio}

Se procederá a analizar la historia legislativa del COGEP con el fin de dar luminarias al texto del procedimiento monitorio, y poder así entender su estructura básica de acuerdo y en armonía con la naturaleza o categoría jurídica que final se le atribuye en la ley. El análisis de la historia legislativa se hará cronológicamente, para poder comparar y contrastar los cambios que sufrió el COGEP mientras se debatía en el Asamblea Nacional.

\footnotetext{
2 Este método de interpretación no está limitado a los países de tradición jurídica continental (civil law), como Alemania, Francia, o Italia. En Reino Unido, cuna de la tradición jurídica anglosajona (common law), se permite la interpretación legal a través del uso de materiales y documentos parlamentarios desde 1993. La jurisprudencia británica consagró a la interpretación histórica en el caso Pepper v Hart, en dicha decisión, se estableció que este método aplica en el siguiente evento: “[...] where (a) legislation is ambiguous or obscure, or leads to an absurdity; (b) the material relied upon consists of one or more statements by a Minister or other promoter of the Bill together if necessary with such other Parliamentary material as is necessary to understand such statements and their effect; (c) the statements relied upon are clear" (Pepper (Inspector of Taxes) v Hart [1992] UKHL 3). Para mayor información sobre este precedente, vid. Elliot, C. y Quinn, F. (2009). English Legal System. 10a Ed. Harlow: Pearson Longman Limited; Beaulac, S. (1998). Parliamentary Debates in Statutory Interpretation: A Question of Admissibility or of Weight?. Mc Gill Law Journal 43, 287-324.
} 


\subsection{El procedimiento monitorio da inicio a un proceso de naturaleza mixta}

El procedimiento monitorio es conceptuado normativamente por primera vez en el Proyecto de Código de Procedimiento Civil elaborado por el Instituto Ecuatoriano de Derecho Procesal ("IEDP") y patrocinado por ProJusticia (i.e. la Unidad de Coordinación para la Reforma de la Administración de Justicia del Ecuador, entonces adscrita a la ex Corte Suprema de Justicia), publicado en diciembre de 2007.

Este proyecto de código adjetivo, impulsado por los profundos cambios constitucionales y legales dados entonces en el Ecuador, tenía como finalidad "lograr una administración de justicia más eficaz" y estaba sustentado en gran medida en "[...] las Bases [sic] que propuso el Instituto Iberoamericano de Derecho Procesal (IIDP) en 1988 con su Proyecto de Código Procesal Civil modelo para Iberoamérica” (Aguirre Guzmán, 2013, p. 117).

Es en la exposición de motivos donde por primera vez hizo referencia al procedimiento que analizamos, el IEDP manifestó: “[...] se introduce una nueva categoría, hasta ahora desconocida por la tradición jurídica ecuatoriana pero prevista en numerosas legislaciones procesales modernas: el juicio monitorio" (2007, p. 31). Dicha exposición de motivos, además, explicaba la finalidad, concepto, estructura, y hasta buscaba darle una definición a este nuevo tipo de proceso:

En el Título IV se regula el proceso monitorio, institución que se encuentra a medio camino entre el proceso de conocimiento y el juicio ejecutivo. El proceso monitorio busca esencialmente dotar de una protección jurisdiccional más enérgica al derecho de crédito, sobre todo para aquellas deudas dinerarias que, por no estar incorporadas a títulos ejecutivos, no gozan de esa especial protección que el sistema —identificado en el actual Código de Procedimiento Civil como "juicio ejecutivo" - [sic] otorga a dichos títulos.

A brevísimos rasgos, es necesario transcribir algunos conceptos que orientarán a definir que es el proceso monitorio. Para Cabenellas, es aquel que "[...] obtiene o pretender lograr por medio de [la] unilateral actuación jurisdiccional un título ejecutivo para ulterior efectividad”. Correa Delcasso seńala que el proceso monitorio es "[...] aquel proceso especial, plenario rápido que tiende, mediante la inversión de la iniciativa del contradictorio, a la rápida creación de un título ejecutivo con plenos efectos de cosa juzgada en aquellos casos que determina la ley." Así pues, a través de este proceso se pueden reclamar y cobrar obligaciones que no resulten controvertidas, de una forma rápida, sencilla y eficaz. Resulta especialmente atractivo para el cobro de deudas dinerarias de pequeñas cuantías; desde ya hay que recalcar que este ha sido un tema obviado por nuestro proceso civil, y el descontento es mayor cuando los procesos para su realización son por demás lentos y gravosos.

La oposición (que, por lo demás, es tasada) al requerimiento de pago formulado por el acreedor, se convierte en demanda, contra quien inició el procedimiento, pues éste debe contestarla y referirse a los motivos que tiene el deudor para no cancelar lo reclamado. En todo caso, se exige el acompañamiento de la prueba que sea menester; y se sanciona enérgicamente a quien no demuestra la existencia de la deuda, como a aquel que se opone sin fundamento. De ahí la afirmación de que es un juicio camino entre el proceso de conocimiento y el de ejecución (2007, p. 34).

En efecto, el Proyecto de Código de Procedimiento Civil (2007) introdujo al procedimiento 
monitorio como una nueva categoría de procedimiento o vía, que daría inicio a un proceso ${ }^{3}$ distinto a los ya conocidos procesos de conocimiento ${ }^{4}$ y de ejecución ${ }^{5}$. Esto se confirma de la geografía del proyecto, pues este procedimiento estaba ubicado en un título propio, el Título IV ("proceso monitorio") del Libro III ("desarrollo de los procesos"). Los procesos de conocimiento y los de ejecución, por otro lado, estaban regulados en los títulos III y V respectivamente. En este proyecto, el título que regulaba al procedimiento monitorio englobaba siete artículos, del 347 al 353.

Es realmente importante lo que estos primeros esbozos revelan sobre la naturaleza originaria del proceso monitorio: no era un proceso de conocimiento, ni uno de ejecución; este era un proceso de su propia categoría, que se encontraba en un limbo entre ambos tipos de procesos. Como señala el proyecto, este era un proceso "a medio camino" entre los procesos de conocimiento y de ejecución (IEDP, 2007, p. 34); por lo tanto, podría decirse que era un proceso mixto, que compartía tanto características cognitivas como ejecutivas. Confrontando esta explicación con la redacción de los artículos del Proyecto de Código de Procedimiento Civil (2007), se puede indicar que, en este borrador, el proceso monitorio:

1. Se rige por un procedimiento sumarísimo ${ }^{6}$, que da origen a un proceso en el cual el fin del actor es probarle al juez la verosimilitud de un crédito en numerario y de baja cuantía, a través de distintas clases de documentos que no constituyan título ejecutivo. Este proceso es de conocimiento, limitado a la prueba de un crédito documental, en el que no existe controversia o contradicción puesto que no participa el demandado (Art. 347).

2. El actor inicia este proceso con una petición (o reclamo de pago) y no con una demanda. En la petición no se prohíbe la solcitud de medidas cautelares (Arts. 348 y $\left.349, n^{\circ} 1\right)$.

3. Si la petición cumple con todos los requisitos (incluido el requisito indispensable y esencial de adjuntar el soporte documental del crédito que busca probarse), el juez procede a dictar, inaudita parte (i.e. el demandado, supuesto deudor), un auto interlo-

\footnotetext{
3 Entiéndase por proceso la relación jurídica compleja, tutelada por una autoridad, que se desenvuelve a través de una serie de actos que ocurren cronológicamente y que constituyen el desarrollo de la relación. Esta relación, que surge del ejercicio de una acción y el cumplimiento de determinados presupuestos, va dirigida a un fin jurídico en particular; ata a los intervinientes mientras subsiste, y es fuente de derechos, obligaciones, potestades, y cargas para estos. Proceso no debe confundirse con procedimiento (vía), que es el conjunto de actos reglados que deben seguirse para constituir y llevar a cabo un proceso. Pese a que esta simple secuencia de actos ocurren dentro de un proceso, no se identifica con este (Devis Echandía, 2002, pp. 168-171).

4 La doctrina nacional concibe al proceso de conocimiento como el proceso en el que un juez "[...] examina los hechos y las pruebas aportadas por ambas partes, efectúa su valoración a la luz del ordenamiento jurídico vigente y formula la norma individual que en lo sucesivo ha de regir la conducta de aquellas con respecto al caso que motivó el proceso (declaración de certeza de la existencia o inexistencia del derecho pretendido por el actor)" (Jijón Letort, 2000, p. 78). Para Devis Echandía, en este tipo de proceso, "[...] el juez regula un conflicto singular de intereses, y determina quién tiene el derecho, es decir, el juez es quien ius dicit” (2002, p. 165).

5 A diferencia del proceso de conocimiento, en el proceso de ejecución "[...] no hay tal declaración ya que se asume la certeza del derecho al arranque del juicio [...]”. Según la doctrina nacional, este tipo de proceso "[...] tiene por objeto hacer efectivo un derecho cierto, cuya satisfacción se tiende a asegurar mediante el empleo de la coacción” (Jijón Letort, 2000, p. 78). En palabras de Devis Echandía, existe proceso de ejecución cuando "no se trate de una pretensión discutida que implique la necesidad de declarar quién tiene razón, sino de una pretensión cuya existencia aparece clara y determinada en el título que se aduce pero que está insatisfecha, porque el obligado no ha cumplido su obligación correlativa” (2002, p. 165).

$6 \mathrm{El}$ procedimiento sumarísimo es aquel en el que "en el menor tiempo posible tiene que alcanzar una resolución judicial" (Cruz Bahamonde, 1995-1998, vol. I, p. 195). En este tipo de procedimiento "sólo se requiere la justificación de la apariencia o verosimilitud del derecho invocado, por cuya razón su característica fundamental es la de la máxima simplicidad formal" (Palacio, 2003, p. 78).
} 
cutorio en el que aprueba la petición del actor y ordena el pago del crédito pretendido, junto con los daños y perjuicios, costas y honorarios (Art. 349, no 2).

4. Conforme al eminente criterio de Cabanellas y de Correa Delcasso (IEDP, 2007, p. 34), el auto interlocutorio contiene una orden de pago que constituye título ejecutivo. El crédito que se ordena pagar, en virtud de estar contenido en un título ejecutivo ${ }^{7}$, goza de una presunción legal ${ }^{8}$ de legitimidad ${ }^{9}$. Este crédito comienza a devengar el máximo interés convencional, más un recargo del cincuenta por ciento, desde que se dicta (Art. 352). El auto interlocutorio es ordenado a citar junto con la petición (Art. $\left.349, \mathrm{n}^{\circ} 1\right)$.

5. Una vez citado el auto interlocutorio, el demandado tiene la opción de oponerse a dar cumplimiento con la orden de pago, dentro de determinado término. Si el demandado no se opone al pago, dentro de tiempo procesal oportuno, el auto interlocutorio queda en firme, y el crédito queda definitivamente reconocido. En consecuencia, el demandado "no puede ya promover cuestión alguna, porque se lo impide la cosa juzgada” (Alsina, 1956-1965, vol. V, p. 38). Termina el proceso monitorio y empieza el proceso de ejecución (Art. 349, no 3).

6. Si el demandado se opone al pago del crédito, también acaba el proceso monitorio. La oposición del demandado es considerada como una demanda que impugna la orden de pago. En este momento, el juez le notifica la demanda al actor del proceso monitorio, iniciando un proceso abreviado (i.e. proceso sumario, según el COGEP) en el cual el nuevo actor (i.e. el demandado en el proceso monitorio) debe justificar sus razones para no acatar la orden (título ejecutivo) que manda a pagar el crédito ${ }^{10}$ (Art. 350).

\subsection{El procedimiento monitorio da inicio a un proceso de naturaleza cognitiva}

Según la Dra. Vanesa Aguirre Guzmán, el Proyecto de Código de Procedimiento Civil (2007) "[...] fue objeto de una nueva revisión en 2009 para ajustarlo a la Constitución del Ecuador del 2008 y al Código Orgánico de la Función Judicial” (2013, p. 117). Más tarde, y con aun más adecuaciones, el proyecto se convirtió en el Proyecto de Código Orgánico General de Procesos, que fue presentado a la Asamblea Nacional por los sucesores de ProJusticia (i.e. el Consejo de la Judicatura, "CJ", y la Corte Nacional de Justicia, "CNJ") en enero de $2014^{11}$.

En este proyecto se dejó de reconocer al proceso monitorio como uno de naturaleza mixta (con elementos de conocimiento y de ejecución), y se pasó a bautizarlo como proceso

\footnotetext{
$7 \mathrm{El}$ autor ecuatoriano Velasco Célleri describe los títulos ejecutivos como “[...] instrumentos a los que la ley les reviste de una vehemente presunción de autenticidad, presunción que solamente puede ser destruida, mediante la prueba que debe rendir el que impugna en juicio [...]" (1996, p. 19). Cruz Bahamonde, también ecuatoriano, comparte el criterio y señala que en el derecho ecuatoriano, "[...] el título goza de presunción de autenticidad" (1995-1998, vol. V, p. 84).

8 Las presunciones legales (iuris tantum) admiten prueba en contrario; las presunciones de derecho (iuris et de iure) no admiten (Borja, 1901, p. 446-448).

9 La ley le brinda una presunción legal de legitimidad al crédito contenido en el título ejecutivo (Alsina, 1956-1965, vol. V, p. 38).

10 En la controversia que surge de un proceso monitorio, la carga de la prueba pesa sobre el que impugna la orden de pago. La carga de prueba no pesa sobre el que pretende el crédito que el juez manda a pagar a través de la orden de pago, debido a que el crédito contenido en la orden (título ejecutivo) se presume legítimo; en palabras de Florencio García Goyena: "El que tiene á [sic] su favor la presunción legal, está dispensado de la prueba” (Borja, 1901, p. 445).

11 Cabe señalar que, paralelamente al proyecto descrito, el Consejo de la Judicatura desarrolló un proyecto de ley adjetiva denominado Proyecto de Código Orgánico General del Proceso, conformado por 421 artículos, cuyo borrador fue publicado en agosto de 2012. Este borrador "[...] tuvo como antecedente un proyecto de "Código Procesal Unificado", elaborado por técnicos chilenos del Centro de Justicia para las Américas (CEJA). [...] Los técnicos del Consejo de la Judicatura [bautizaron] a su propuesta como "ecléctica" (en cuanto busca un término medio entre el proceso civil estadounidense y el anteproyecto del Instituto Iberoamericano)” (Aguirre Guzmán, 2013, p. 117).
} 
de conocimiento, enfatizando así su aspecto cognitivo (i.e. la evaluación del documento que probaría al crédito, como antecedente a la orden ejecutiva de pago). La exposición de motivos del Proyecto de Código Orgánico General de Procesos (2014) introdujo este cambio de la siguiente manera: "En el Libro Cuarto se consignan los Procesos y dentro de estos a los denominados de Conocimiento: Ordinario; Sumario y Monitorio" (CJ y CNJ, 2014, p. 12). Más adelante, la exposición de motivos desarrolló la idea del proceso monitorio de la siguiente manera:

En los procesos de conocimiento enunciados, el proyecto plantea la necesidad de normar tres tipos: el proceso ordinario, aplicable a todas las causas que no tengan una vía de sustanciación previamente establecida en la ley; el proceso sumario para ventilar causas mercantiles, derechos personas y deudas dinerarias de baja cuantía que no sean exigibles por otra vía; y el procedimiento monitorio, a través del cual se pueden cobrar deudas de baja cuantía que no constituyan título ejecutivo. En este proceso, el juez o la juez tendrán amplias facultades para valorar la petición y de considerarlo procedente, ordenar el pago dentro de determinado plazo (CJ y CNJ, 2014, p. 16).

En efecto, en la geografía de este proyecto, el procedimiento monitorio se encontraba encerrado en el Capítulo III ("proceso monitorio") del Título I ("procesos de conocimiento") de su Libro IV (“de los procesos"). Su número de artículos se redujo, de siete a seis, de los artículos 361 al 366. No obstante, este cambio no afectó a la estructura del procedimiento monitorio, ni a las a implicaciones conceptuales que surgían del mismo. Hubo otros cambios, pero menores. Se ańadió la posibilidad de reclamar por esta vía créditos laborales (Art. 361, no 5), y se agregó una forma especial de citación por notario o agente de la fuerza pública (Art. 363, $\mathbb{\$}$ 1). Se eliminó el recargo del cincuenta por ciento, y se cambió el génesis del interés máximo convencional (Art. 365). De igual manera, se eliminó la expresa mención de la condena al pago de dańos y perjuicios, costas, y honorarios; y el artículo referente a los efectos de la cosa juzgada, disposiciones que constaban en el Art. 349, no 2; y 351 del Proyecto de Código de Procedimiento Civil (2007), respectivamente.

Hasta ese momento, sin tomar en consideración el cambio de la naturaleza jurídica del proceso que origina, el procedimiento monitorio como tal se mantenía relativamente sin cambios. Una vez ingresado el proyecto a la Asamblea Nacional es que este comenzó a mutar considerablemente. La Comisión de Justicia y Estructura del Estado (“CJEE”), órgano de la Asamblea Nacional encargado del proyecto, presentó el Informe para Primer Debate del Proyecto de Código Orgánico General de Procesos en julio de 2014. El análisis particular que este órgano le dio al procedimiento monitorio es el que se cita a continuación:

El proceso monitorio es una de las novedades incorporadas en el Proyecto, institución desarrollada por otras legislaciones que han servido de ejemplo para la implementación del mismo en nuestra legislación. Una de las legislaciones tomadas en cuenta para incluir al procedimiento monitorio en el Proyecto fue la de Uruguay, cuyo procedimiento viene desde el siglo pasado y que la nueva ley lo incluyó porque tuvo una aplicación exitosa. En dicha legislación se señala que el procedimiento monitorio procede en los casos en que el objeto a sustanciar esté dotado de cierto grado de certeza, por ejemplo la existencia de un cheque u otro tipo de documento o título o bien o cuando se ha vencido o no el plazo de un contrato de arriendo. En este caso la o el juez se pronuncia inmediatamente sobre el fondo del asunto 
sin escuchar previamente al demandado. Ese pronunciamiento inicial puede ser favorable o desfavorable; en el caso de que sea favorable al actor, como es un proceso y debe contemplar la contradicción, se abre para el demandado la oportunidad de oponer excepciones. Si no las opone, la sentencia inicial queda firme y es cosa juzgada. Si las opone, el proceso pasa a la estructura ordinaria.

En el Proyecto, se agregó la posibilidad de que el trabajador cuyas remuneraciones mensuales o adicionales de hasta ciento cincuenta remuneraciones básicas unificadas no hayan sido pagadas oportunamente, lo sustancia a través del proceso monitorio.

Cabe mencionar que el procedimiento monitorio no atenta contra el debido proceso porque a pesar de sentenciar al demandado sin haberlo escuchado y sólo con el mérito de lo expuesto por el demandante, este sigue teniendo la posibilidad de exigir la realización de un juicio si se opone a lo resuelto por la o el juez. La garantía de un juicio justo sigue siendo una posibilidad que depende de la voluntad de la persona a quien protege y que quien sea el demandado se oponga.

Conforme las observaciones presentadas por la Corte Nacional de Justicia y el Consejo de la Judicatura, se estableció que el proceso monitorio iniciará con la interposición de una demanda y no de una petición conforme disponía el proyecto original.

Adicionalmente, se retiró del artículo 362 del Proyecto los numerales que contenían varios requisitos respecto de la petición, ya que el demandante tendrá la posibilidad de hacer uso de los formatos elaborados por el Consejo de la Judicatura para el efecto (CJEE, 2014, pp. 25-26).

Este informe del proyecto resume todos los cambios que sufrió el borrador del código a ser discutido en primer debate parlamentario. Respecto de la geografía, se mantuvo sin cambios; en este borrador, el procedimiento monitorio se ubicó en el Capítulo III ("Proceso monitorio") del Título I ("Procesos de conocimiento") del Libro IV ("Procesos"), con seis artículos en total, del 344 al 349.

En cuanto a la estructura, el procedimiento monitorio cambió inmensamente. Como evidencia este informe, el proceso monitorio pasó de iniciar con una petición a iniciar con una demanda. Este proceso se independizó de las reglas del procedimiento sumario, y el procedimiento monitorio expuesto en este informe introdujo una segunda etapa, compuesta por audiencia única y que termina con sentencia. Adicionalmente, se estableció expresamente que de la sentencia dictada en este proceso caben únicamente los recursos de aclaración, ampliación, y apelación. Por otro lado, se eliminó la posibilidad de peticionar medidas cautelares, de reformar la demanda y de reconvenir. En resumen, en el Informe para Primer Debate (2014), se contempló un proceso monitorio que:

1. Se compone por dos etapas procesales: una primera etapa necesaria y una segunda contingente. La primera etapa es de conocimiento limitado pero sin controversia o contradicción, en la que el actor prueba la verosimilitud de un crédito en numerario y de baja cuantía, a través de distintas clases de documentos que no constituyan título ejecutivo (Art. 344). 
2. La primera etapa del proceso monitorio inicia con una demanda (Art. 345), que no admite reforma, solicitud de medidas cautelares, o reconvención (Art. 347, \$2). Si la demanda cumple con todos los requisitos legales, el juez dictará, inaudita parte, un auto interlocutorio que aprueba la petición del actor y ordena el pago del crédito pretendido (Art. 346, $\$ 1$ ).

3. La naturaleza de la orden de pago contenida en el auto interlocutorio es la de un título ejecutivo, y por lo tanto, el crédito ordenado a pagar goza de una presunción legal de legitimidad. El auto interlocutorio es ordenado a citar junto con la demanda (Art. 346 , $\$ \$ 1-2)$. El crédito pretendido comienza a devengar el máximo interés convencional, desde que se realiza la citación (Art. 348).

4. Citado el auto interlocutorio, el demandado tiene la facultad de oponerse a la orden de pago dentro de determinado término. Si no se opone dentro de tiempo procesal oportuno, el auto interlocutorio queda en firme y se convierte en título de ejecución. Termina el proceso monitorio como tal y empieza el proceso de ejecución (Art. 346, \$3).

5. Si el demandado se opone, no acaba el proceso monitorio. La oposición del deudor en contra de la orden de pago del crédito contenida en el auto interlocutorio da inicio a la segunda etapa del proceso monitorio. Esta segunda etapa es plenamente cognitiva. El juez procede a notificarle la oposición del demandado al actor y los convocará a una audiencia única de conciliación, pruebas, y alegatos. Si se entra a segunda etapa, el proceso monitorio termina en sentencia, que constituye título de ejecución. De esta sentencia únicamente caben los recursos de aclaración, ampliación, y apelación (Art. $347, \$ 1)$.

\subsection{El procedimiento monitorio da inicio a un proceso de naturaleza ejecutiva}

En el Informe para Segundo Debate, de febrero de 2015, se le asignó al proceso monitorio una naturaleza jurídica completamente diferente: la de un proceso de ejecución. Así se lo explicó en el contenido del informe:

Se incluye en el Libro IV un procedimiento innovador y novedoso, que viene a solucionar graves injusticias que se cometen en contra de los acreedores que no podían cobrar sus créditos por falta de un título ejecutivo, lo que hacía que las deudas no sean honradas por lo deudores, que deviene en un alto grado de morosidad, creando inseguridad en el sistema económico y atentando contra la confianza y la buena fe.

El procedimiento monitorio es un procedimiento judicial creado con el objetivo primordial de cobrar de manera rápida y sencilla deudas determinadas de dinero. Es un procedimiento especial dado que se invierte el contradictorio, es decir, que sin haber escuchado aún al demandado, el juez le ordena el pago desde la resolución inicial, dándole para tal efecto un plazo de quince días.

El avance dogmático se refleja en que se procederá a la ejecución directamente si el deudor no comparece dentro del término concedido o si lo hace sin manifestar oposición, y además tendrá el efecto de cosa juzgada, y se procederá al embargo de los bienes del deudor que el acreedor ha señalado. No existe para este tipo de procedimiento el recurso de casación (CJEE, 2015, p. 26). 
$\mathrm{Al}$ parecer, se hizo especial énfasis en el aspecto ejecutivo del proceso monitorio (i.e. la constitución de un título ejecutivo a favor del actor, sin que se escuche previamente al demandado ${ }^{12}$ ). Se hizo también énfasis en la no admisión del recurso extraordinario de casación en este tipo de proceso. Geográficamente, la posición del procedimiento monitorio cambió: pasó a ser regulado en el Capítulo II ("Procedimiento monitorio") del Título II ("Procedimientos ejecutivos") del Libro IV ("Procesos"). En cuanto a los artículos, su número se mantuvo en seis, del 376 al 381. Dichos artículos conservaron la misma redacción que en el borrador anterior, y por ello, se puede decir que su estructura bipartita no cambió.

El cambio de naturaleza efectuado en el Informe para Segundo Debate (2015) no necesariamente le niega aspectos cognoscitivos del proceso monitorio. En marzo de 2015, el Pleno de la Asamblea Nacional sancionó el Texto Aprobado del Proyecto de Código Orgánico General de Procesos, en el que se eliminó la prohibición de medidas cautelares (Art. 359, \$2). Este texto fue enviado al Presidente de la República, quien en abril de 2015, en su calidad de colegislador, manifestó: "El proyecto contiene entre sus disposiciones la previsión de un procedimiento monitorio, caracterizado por la simplificación de la fase cognoscitiva, para pasar en la medida de lo posible de forma ágil a la de ejecución" (2015, p. 44).

Este comentario constante en la Objeción Parcial (2015) del Presidente confirma el aspecto cognoscitivo del proceso monitorio, aspecto que caracteriza a su segunda etapa (un mini proceso sumario en todo menos en nombre, como lo confirma su estructura y su historia). Esto no quiere decir que el Presidente haya contradicho el texto del COGEP (i.e. que haya dicho que el proceso monitorio es uno de conocimiento y no uno de ejecución). Podría decirse que el proceso monitorio es prima facie, un proceso de ejecución (i.e. la primera etapa en la que se constituye un título ejecutivo), y dependiendo del actuar del deudor, este podría mutar a uno de conocimiento (i.e. la segunda etapa en la que se impugna la orden de pago que se manda a pagar el crédito perseguido). Aceptada la Objeción Parcial (2015), el COGEP fue promulgado y posteriormente publicado en el Registro Oficial.

\section{El procedimiento monitorio vigente a la luz de la historia legislativa. Conclusión}

Un análisis íntegro y cronológico de los trabajos preparatorios y documentos legislativos del COGEP: 1. Proyecto de Código de Procedimiento Civil (2007); 2. Proyecto de Código Orgánico General de Procesos (2014); 3. Informe para Primer Debate (2014); 4. Informe para Segundo Debate (2015); 5. Texto Aprobado (2015); y, 6. Objeción Parcial (2015); permite concluir el texto oficial de este código adjetivo que concibe al proceso monitorio de la siguiente manera:

1. El proceso monitorio se divide en dos etapas. La primera etapa es necesaria y es de naturaleza ejecutiva, pues sólo intervienen el actor y el juez, y no se resuelven pretensiones contrapuestas. Por este motivo, el procedimiento monitorio se encuentra ubicado en el Título II del Libro IV del COGEP.

2. En la primera etapa del proceso monitorio, el actor debe probarle al juez, a través de cualquiera de las distintas clases de documentos probatorios listados (e.g. facturas, recibos, etc.), la verosimilitud de un crédito en numerario (líquido, exigible, y de plazo vencido) y de baja cuantía (actualmente, cincuenta salarios básicos unificados del trabajador en

\footnotetext{
12 El legislador considera que los procesos de conocimiento son aquellos en los que siempre existen "[...] pretensiones contrapuestas, que debe resolver el juez declarando a quien pertenece el derecho cuestionado o la cosa litigiosa. En los procesos de conocimiento siempre hay disputa, siempre hay dos partes" (CJEE, 2015, p.25). Por ello, si en el proceso monitorio no existen pretensiones contrapuestas o una disputa entre dos partes sino hasta que el demandado manifiesta oposición, no podría considerarse a este proceso como uno de conocimiento, por lo menos en su primera etapa.
} 
general), siempre y cuando este crédito no conste en título ejecutivo (Art. 356).

3. La primera etapa del proceso monitorio inicia con una demanda, que puede ser propia o mediante un formulario provisto por el Consejo de la Judicatura (Art. 357), que no admite reforma o reconvención (Art. 359, \$2), pero sí la solicitud de medidas cautelares. Si la demanda cumple con todos los requisitos (incluyéndose el requisito fundamental de adjuntar la prueba documental, constante en el Art. 356), el juez procederá a dictar, inaudita parte, un auto interlocutorio en el que ordena el pago del crédito pretendido (Art. 358, \$1).

4. La orden de pago contenida en el auto interlocutorio constituye título ejecutivo. En consecuencia, el crédito que se manda a pagar en la orden de pago goza de una presunción legal (iuris tantum) de legitimidad. El juez procede a ordenar citar el auto interlocutorio junto con la demanda (Art. 358, $\$ \$ 1-2$ ). El crédito comienza a devengar el máximo interés convencional desde que se realiza la citación al demandado (Art. 360).

5. Citado el auto interlocutorio, el demandado tiene la opción de oponerse, dentro de determinado término. Si este no se opone dentro de tiempo procesal oportuno, el auto interlocutorio queda en firme, y se convierte en título de ejecución. En consecuencia, en virtud de los efectos de cosa juzgada del auto interlocutorio, el crédito queda definitivamente reconocido. Termina el proceso monitorio como tal y empieza el proceso de ejecución (Art. 358, \$ 3).

6. Si el demandado se opone a la orden de pago, no acaba el proceso monitorio. La oposición del demandado da inicio a la segunda etapa del este tipo de proceso. La segunda etapa del proceso monitorio es de naturaleza plenamente cognitiva; en ella el demandado debe impugnar justificadamente la orden de pago (título ejecutivo). Debido a que el actor goza de una presunción legal a través del título ejecutivo, la carga de la prueba se invierte en contra del demandado.

7. En la segunda etapa del proceso monitorio, el juez le notifica la oposición del demandado al actor y procede a convocarlos a una audiencia única. Esta audiencia es idéntica a la del procedimiento sumario. Si se entra a segunda etapa, el proceso monitorio termina en sentencia, que constituye título de ejecución. De esta sentencia únicamente caben los recursos de aclaración, ampliación, y apelación; no cabe el recurso extraordinario de casación (Art. 359, \$1).

\section{Referencias bibliográficas}

Aguirre Guzmán, V. (2013). Líneas para un proceso de reforma a la justicia civil en Ecuador. Revista Iuris Dictio, 13(15), 113-130. https://doi: 10.18272/iu.v13i15.718

Alsina, H. (1956-1965). Tratado Teórico Práctico de Derecho Procesal Civil y Comercial. Vols. I-VII. 2a Ed. Buenos Aires: Ediar.

Beaulac, S. (1998). Parliamentary Debates in Statutory Interpretation: A Question of Admissibility or of Weight? McGill Law Journal, 43, 287-324.

Borja, L. F. (1901). Estudios sobre el Código Civil Chileno. Vol. I. París: A. Roger y F. Chernoviz. Cruz Bahamonde, A. (1995-1998). Estudio Crítico del Código de Procedimiento Civil. Vols. I-V. Guayaquil: Edino.

Devis Echandía, H. (2002). Teoría General del Proceso. 3a Ed. Buenos Aires: Editorial Universidad. 
Elliot, C. y Quinn, F. (2009). English Legal System. 10a Ed. Harlow: Pearson Education Limited. Enneccerus, L., Kipp, T., y Wolff, M. (1953). Tratado de Derecho Civil. Vol. I. (B. Pérez González y J. Alguer, trads.). Barcelona: Bosch, Casa Editorial. https://doi.org/10.2307/837141

Jijón Letort, R. (2000). La casación en los juicios ejecutivos. Revista Iuris Dictio, 1(1), 77-83. doi: $10.18272 /$ iu.v1i1.477

Messineo, F. (1979). Manual de Derecho Civil y Comercial. Vol. I. (S. Sentís Melendo, Ed. \& trad.). Buenos Aires: Ediciones Jurídicas Europa-América.

Palacio, L. E. (2003). Manual de Derecho Procesal Civil. 17a Ed. Buenos Aires: Abeledo Perrot.

Planiol, M. y Ripert, G. (1999). Derecho Civil. (L. Pereznieto Castro, trad.). México D.F.: Oxford University Press.

Velasco Célleri, E. (1996). Sistema de Práctica Procesal Civil. Vol. III. 2a Ed. Quito: Editorial Pudeleco.

\section{Legislación}

Asamblea Nacional de la República del Ecuador (2005). Código Civil del Ecuador. Codificación No. 2005-010. Suplemento del Registro Oficial No. 46, 24 de junio del 2005.

Asamblea Nacional de la República de Ecuador (2015). Código Orgánico General de Procesos. Suplemento del Registro Oficial No. 506, 22 de mayo del 2015.

\section{Proyectos normativos}

Bello. A (1888). Proyecto de Código Civil (1853). En Obras Completas de Don Andrés Bello. Vol. XII. Ed. Consejo de Instrucción Pública de Chile. Santiago de Chile: publicado por Pedro G. Ramírez.

Consejo de la Judicatura y Corte Nacional de Justicia (2014). Proyecto de Código Orgánico General de Procesos.

Instituto Ecuatoriano de Derecho Procesal (2007). Proyecto de Código de Procedimiento Civil. Patrocinado por ProJusticia.

\section{Observaciones, opiniones, aprobaciones e informes:}

Comisión de Justicia y Estructura del Estado (2014). Informe para Primer Debate, Proyecto de Código Orgánico General de Procesos.

Comisión de Justicia y Estructura del Estado (2015). Informe para Segundo Debate, Proyecto de Código Orgánico General de Procesos.

Pleno de la Asamblea Nacional (2015). Texto Aprobado, Proyecto de Código Orgánico General de Procesos.

Presidencia de la República del Ecuador (2015). Objeción Parcial, Proyecto de Código Orgánico General de Procesos. 